\title{
COLOMBIA: LA GUERRA IRREGULAR EN EL FIN DE SIGLO*
}

\author{
Alfredo Rangel Suárez**:
}

\section{LOS CAMBIOS EN LA GUERRILLA}

La búsqueda de soluciones a la guerra irregular que se desarrolla en Colombia requiere una comprensión objetiva y realista de la naturaleza del fenómeno guerrillero y de la dinámica actual de su enfrentamiento con el Estado.

Estimamos que en muchos sectores de la opinión subsiste una visión de la guerrilla y del conflicto que ya no corresponde a la realidad. Esta incomprensión de la naturaleza del fenómeno está en la base de la subestimación de la dimensión de la amenaza que representa para el país una guerrilla que, de continuar con los ritmos de crecimiento y expansión de la última década, antes de ocho años podría tener cerca de treinta mil hombres en armas y alrededor de trescientos frentes de combate irregular. De llegar a cifras cercanas a este crecimiento cuantitativo, serían muy grandes las posibilidades de que la actual guerra de guerrillas dé el salto cualitativo hacia la generalización de la guerra de movimientos y hacia la guerra de posiciones, salto que tendría como requerimiento indispensable la transformación de las guerrillas en ejércitos regulares.

El punto es que por primera vez en su historia las guerrillas en Colombia se están viendo ante la posibilidad cierta de lograr estos propósitos estratégicos, y que es precisamente esta percepción del desarrollo del conflicto lo que les estaría condicionando sus posiciones frente a la guerra y frente a la paz. Pero a esta situación se ha llegado como resultado de una serie de circunstancias que tienen que ver con el acomodamiento y aprovechamiento exitoso, por parte de las guerrillas de los cambios y circunstancias que ha vivido el país desde la tormentosa década de los ochenta.

Para empezar, la guerrilla ha redefinido sus objetivos. La revolución socialista latinoamericana y la construcción del hombre nuevo han cedido paso al dominio político de los municipios de Colombia y a la creación de clientelas a través de la acción armada. Su aspiración a tomarse el poder nacional y elaborar planes quinquenales para edificar el socialismo fue sustituida por la imposición de planes de desarrollo municipal que orientan los recursos de inversión pública hacia sus clientelas y le garantizan recibir, de parte de los contratistas, un porcentaje del valor de los contratos de las obras públicas. Y es que la guerrilla durante los quince años anteriores no ha estado empeñada en derrotar militarmente al Ejército ni en tomarse el poder central del país; se ha concentrado en sacar a la Policía del mayor número posible de pueblos para tomarse muchos poderes locales y así ampliar su dominio territorial con el fin de tener más capacidad de negociación cuando llegue el momento oportuno para hacerlo.

También han cambiado sus medios. Antes la guerrilla se armaba tendiendo emboscadas a la fuerza pública para arrebatarle los fusiles a los caídos -en sus términos, "recuperar las armas"-; era su única opción ante el siempre exiguo apoyo internacional y la pobreza franciscana de sus columnas. La confrontación militar le posibilitaba a la guerrilla su expansión territorial, puesto que era su fuente de armamento: a mayor confrontación, más armamento. El combate militar era el medio irrenunciable para su expansión. Ahora esas "recuperaciones" tienen importancia marginal ante el amplio acceso de la guerrilla a los innumerables canales del mercado negro internacional de armas, acceso garantizado por los enormes recursos económicos que le aporta el uso calculado y constante del terror con fines económicos.

Antes la guerrilla se financiaba principalmente recurriendo a asaltos bancarios, apoyos voluntarios de los campesinos y una que otra vacuna o robo a algún ganadero o campesino rico; no estaba entre sus fuentes de recursos ni la industria del secuestro -cerca de la mitad de los secuestros en Colombia, país donde ocurre el $45 \%$ de los secuestros del mundo entero son realizados por la guerrilla ${ }^{1}-$, ni el narcotráfico, ni la extorsión generalizada. No había incursionado en los sectores que son grandes fuentes de divisas: el petróleo, el carbón, el oro... la coca y la amapola. Tampoco se nutría, como hoy, de los fiscos municipales. Durante los años recientes, en conjunto, la guerrilla ha logrado articular estrategias financieras supremamente exitosas que le significan ingresos superiores a los mil millones de pesos diarios.

Este artículo corresponde al capítulo I de su libro Colombia: Guerra en el fin de siglo, editado por Tercer Mundo Editores y la Facultad de Ciencias Sociales de la Universidad de los Andes, Bogotá, Agosto de 1998.

** Economista y Magister en Ciencia Política. Ex asesor presidencial de seguridad nacional, catedrático e investigador de la Universidad de los Andes.

1. El Tiempo, 27 de octubre de 1996, pág. 22A. 
Estas cantidades ingentes de recursos que hoy maneja la guerrilla ha ocasionado la distorsión de su imagen y naturaleza en muchos sectores que ven, equivocadamente, en los grupos insurgentes sólo un negocio para el enriquecimiento personal de cada uno de sus integrantes. Nada más errado y peligroso que esta interpretación. De ser así, las guerrillas serían solamente unos grupos de bandoleros o de delincuentes comunes que tarde o temprano correrían la misma suerte de los fenómenos bandoleriles en todas las latitudes: su extinción como producto de las vendettas internas, o su desintegración más o menos indolora. Por tanto, una política estatal de paz saldría sobrando y, parodiando la conocida cita, habría que sentarse en la puerta y esperar a ver pasar el cadáver de la guerrilla. No. La guerrilla ha hecho del dinero no un fin en sí mismo sino un medio, uno de sus principales recursos políticos y, obviamente, el sostén e impulsor de su capacidad bélica.

Los partidos tradicionales y sus dirigentes siempre fueron blanco de sus más radicales discursos; ahora la transacción y la componenda con facciones locales de esos partidos es una de las principales tácticas para garantizar su presencia y su influencia local. Por eso, cuando alguien proponía como solución al problema guerrillero la cooptación política de los insurgentes olvidaba que son los guerrilleros los que ya están cooptando políticamente a los dirigentes locales de los partidos tradicionales, para quienes esos pactos son perfectamente funcionales cuando se trata de ganar elecciones a las facciones del otro -o del mismo- partido. Ante el dilema de manejar o no unos presupuestos municipales muy robustecidos por la descentralización fiscal y administrativa, para unos y para otros los asuntos ideológicos poco y nada cuentan.

$\mathrm{Si}$ en sus inicios las FARC fueron un movimiento campesino en busca de ideología, y el ELN una ideología en busca de movimiento campesino, hoy ambas fuerzas tienen unas dinámicas militares y políticas propias y autónomas. En sus propósitos la lucha por la tierra ha sido remplazada por la influencia y el dominio territorial. Su gran crecimiento reciente no ha sido alimentado ni por la revuelta social ni por la protesta ideológica. Son grupos armados con una gran capacidad para allegar recursos económicos, para controlar algunos territorios y para mantener una presencia superficial en otros. Sus banderas nacionales no se ven o no son creíbles, pero su clientelismo armado local y su eficaz aprovechamiento del desempleo rural juvenil les permite sobreaguar políticamente y establecer, incluso, bolsones de legitimidad y apoyo en muchas regiones del país.

Como síntesis de lo anterior, podemos decir que los objetivos internacionales de la guerrilla se volvieron municipales y la desproporción que existía entre unos fines pretenciosos - la revolución latinoamericana- y unos medios tan modestos -la "recuperación" de armas- se ha revertido hacia un nuevo balance entre unos fines más modestos -el poder municipal- con unos recursos casi ilimitados. La guerrilla descendió de la ideología al pragmatismo, del redentismo a la realpolitik. Paradójicamente, esto la torna más peligrosa y desestabilizante.

Su composición también ha variado. Si en sus inicios sus filas se nutrían de campesinos y estudiantes altruistas, ahora el reclutamiento se hace con base en campesinos desocupados y colonos, que en muchas ocasiones sólo buscan un salario y una forma de vida. Antes la doctrina mitigaba las penurias propias de la escasez de todo, ahora la ostentación de los más inusitados artículos propios del consumismo urbano contribuye a dar estatus a los jóvenes guerrilleros frente a sus comunidades de origen.

El impacto de la presencia de la guerrilla en el campo también ha cambiado. De personajes más o menos pintorescos, que trashumaban sin descanso por los riscos del país sin provocar mayores reacciones de los pobladores del campo, se ha pasado a ejércitos muy bien pertrechados que causan terror dondequiera su presencia se hace sentir. $\mathrm{Y}$ el resultado es bien distinto: un país que padece la acción de ejércitos privados de todos los pelambres, muy bien armados y equipados por señores de la guerra resueltos a defender a sangre y fuego sus territorios, o a liberarlos de la amenaza de cualquier otro poder armado. Consecuencia: la feudalización del país, su división en comarcas o principados dominados por grupos armados y una escalada de confrontación entre bandas que se han prometido guerra sin cuartel. Lo que, para ser sinceros, tampoco es extraño a la tradición colombiana; recuérdese la homogeneización política municipal que ocasionó la violencia clásica de los años cincuenta, y cómo ella estableció linderos partidistas territoriales durante un buen tiempo ${ }^{2}$. Pero, claro, lo de hoy no tiene parangón con el pasado en términos de disposición de poder económico y de capacidad de destrucción de los nuevos grupos armados irregulares.

Pero tal vez lo que más diferencia la guerrilla de hoy de su pasado ancestral es el uso permanente y sistemático de un arma inédita contra la población civil: el terror masivo. Y esto parece haberla pervertido irremediablemente. La experiencia histórica demuestra que el terror se lo traga todo y quienes se embarcan en él no lo pueden detener, porque no avanza, sino que retrocede. Quienes a él recurren saben dónde comienzan, pero jamás saben cómo ni dónde terminarán. El terror lo devora todo: el esfuerzo, el poder, los medios y los objetivos, aun cuando sea concebido sólo como un eslabón de la estrategia general ${ }^{3}$. En la guerrilla los diques y las restricciones morales parecen haberse roto para siempre. Para ella el problema de establecer los límites permisibles de la violencia -la gran cuestión tanto de la violencia revolucionaria como de la contrarrevolucionaria- ya no existe ${ }^{4}$.

Aun cuando es necesario señalar que en muchas regiones la guerrilla se ha ganado el apoyo voluntario de algunos sectores de la población, al presentarse como solución eficiente de agudos problemas de seguridad, de justicia, de orden y, en general, de falta de Estado, también es imprescindible anotar que en Colombia la guerrilla se ha vuelto terrorista por su búsqueda sistemática, permanente y deliberada de la dominación mediante el terror que produce una

2. DEAS, Malcolm y GAITÁN, Fernando, Dos ensayos especulativos sobre la violencia en Colombia, Fonade, DNP, TM Editores, Bogotá, 1995, pág. 40.

3. IVIANSKI, Zeev, "El problema Moral", en RAPAPORT, David C., La moral del terrorismo, Editorial Ariel, S.A., Barcelona, 1985, pág. 57.

4. Ibídem, pag.17. 
forma de violencia cuyos efectos psicológicos son desproporcionados con respecto a su estricto resultado físico. Mata a uno y atemorizas a diez mil, dice el proverbio chino. Por terrorista, la guerrilla ha dejado de insistir de manera creíble en la humanización del conflicto y en buscar su reconocimiento como fuerza beligerante. Lo primero, porque actuar conforme a las leyes privaría del arma del terror, y le implicaría -al dejar de secuestrar y de extorsionar- privarse de por lo menos el $60 \%$ de sus ingresos económicos, lo cual reduciría en gran medida sus posibilidades de expansión política y de crecimiento militar. Lo segundo, porque después de la debacle comunista ningún Estado estaría hoy dispuesto a reconocer beligerancia a unas fuerzas tan involucradas en el narcotráfico y que violan en forma sistemática el derecho internacional humanitario, sin arriesgarse a ser señalado de connivencia con el narcotráfico y acusado de despreciar el derecho internacional, temas a todas luces prioritarios en la agenda de las relaciones multilaterales.

\section{EL CÁLCULO POLÍTICO Y TEMPORAL DE LA GUERRILLA}

La gran pregunta que resulta de este análisis es si la sociedad y el Estado le están dando hoy la respuesta adecuada a este fenómeno guerrillero que nada tiene que ver con lo que estábamos acostumbrados a presenciar hasta hace sólo unos pocos años. ¿No será que el replanteamiento tiene que ser total? Si consideramos los cambios ocurridos al interior de la guerrilla en cuanto a sus objetivos, sus medios, su composición y su impacto en las regiones, no parecería muy adecuado seguir insistiendo en salidas al conflicto que apelan exclusiva y permanentemente a la buena voluntad de la guerrilla, cuando se trata de un problema de disputa de importantes cantidades de poder real a nivel local y regional.

El conflicto armado con las guerrillas en Colombia tiene que plantearse de manera consecuente como un problema político y asumir todas las consecuencias de este planteamiento. Esto significa reconocer que en la base de su dinámica hay una disputa de poder que está condicionada a las leyes propias de los enfrentamientos políticos y poco tiene que ver con la buena voluntad de los individuos. Es un problema de correlación de fuerzas y de apreciación de las posibilidades del enfrentamiento hacia el futuro.

A la guerrilla el horizonte se le presenta despejado y con muchas posibilidades para fortalecerse económicamente y para ampliar su poder político en las regiones. Tiene mucho espacio por ganar y mucha fuerza por acumular para negociar en superiores condiciones a las actuales cuando llegue el momento oportuno de hacerlo, esto es, el momento más allá del cual no se pueden esperar más ganancias por la vía del conflicto, sino por la vía de la negociación. Por esta razón, para la guerrilla el momento óptimo de iniciar una negociación seria de paz no parece haber llegado todavía.

De ahí que juegue con el tiempo de una manera tan exasperante para la contraparte. La guerrilla maneja hoy la formidable arma del tiempo. No tiene prisa ni le corre afán. Sabe que el tiempo corre a su favor, pues siente que está ganando el conflicto y que cada día que pasa acumula más recursos, más poder y más influencia. Además, para una guerrilla tan campesina corno las FARC, la percepción del tiempo es muy rural, o sea, el tiempo no es un recurso escaso sino abundante y de amplia disposición. Por su parte, para el ELN, un grupo armado profundamente penetrado por una visión religiosa de su supuesta misión redentora de los pobres, el tiempo es percibido en términos casi bíblicos, de generaciones que cumplen su destino y adelantan la lucha hasta un punto que es continuado por las siguientes generaciones. Por el contrario, la percepción del tiempo que tiene el Gobierno es urbana y electoral: urbana, porque lo percibe como un recurso escaso y valioso; electoral, porque el tiempo para el Gobierno es un corto lapso que transcurre entre dos elecciones separadas por sólo cuatro años. Estas percepciones tan distintas están en la base de los ritmos tan diferentes que las dos partes constantemente le han querido imprimir al acercamiento, al diálogo y a la negociación.

Del lado de la guerrilla se une entonces una percepción favorable del desarrollo del conflicto como nunca antes la había tenido, con una percepción del tiempo como un recurso prácticamente ilimitado. Por eso para ella es mejor negocio continuar el conflicto que hacer la paz. Tiene más que ganar en la confrontación que en la negociación. Esto es así, aun cuando las almas cándidas crean que los problemas políticos siempre se pueden resolver apelando principalmente a la buena voluntad del adversario. Si las expectativas son de crecimiento a través del conflicto no hay buena voluntad que valga, y quien al interior de la subversión se oponga a su continuación será arrollado sin consideración. La lucha por el poder impone siempre su lógica inexorable. Del lado del Gobierno, se junta una visión desfavorable de la evolución del conflicto y una percepción del tiempo como un recurso muy escaso. De ahí su insistencia en resolver la confrontación mediante la negociación lo más pronto posible. Frente a esta situación cabe recordar que las teorías de la negociación han establecido que la parte que esté dispuesta a esperar más tiempo, a dar muestras de ser más paciente, de parecer menos ansiosa por llegar a un arreglo, será la que tenga más éxito 5 .

La pregunta que cabe hacerse, entonces, es si realmente estamos frente a un conflicto maduro para negociar, lo que equivale a averiguar si hemos llegado a una situación en que ambas partes perciben que es más lo que pueden ganar por la vía de la negociación que por la vía del conflicto. Las partes enfrentadas en un conflicto cualquiera pueden querer dar fin a la batalla por medio de la negociación cuando ambas reconocen, en primer lugar, que no les es posible conseguir sus propósitos a través del enfrentamiento; en segundo lugar, que sólo pueden lograr sus fines por medio del conflicto a un precio que no quieren o no pueden pagar y, finalmente, que, en general, es menos atractivo continuar el conflicto que hacer la paz ${ }^{6}$.

5. RAIFFA, Howard, El arte y la ciencia de la negociación, Fondo de Cultura Económica, México, 1991, pág.83.

6. COSER, Lewis A., "La terminación del conflicto", en EMITAI y EtZioni, Eva (comps.), Los cambios sociales, Fondo de Cultura Económica, México, 1979, pág.422. 
En nuestro caso, el establecimiento parece haber llegado a estas tres conclusiones hace un buen rato. Por eso busca el diálogo y la negociación de manera persistente. La guerrilla, por el contrario, no parece haber llegado a ninguna de las tres conclusiones: está segura de que puede conseguir sus propósitos inmediatos -más dinero, más poder, más influencia- a través de la acción armada; sabe que el costo que tendrá que pagar no será demasiado alto, dada la escasa capacidad de contención militar y de control político del Estado en las regiones; $y$, en consecuencia, ha llegado a la conclusión de que, por ahora y tal vez por un buen tiempo, es más atractivo continuar el conflicto que hacer la paz. Son cálculos que puede hacer la guerrilla, no obstante haber incorporado seguramente la negociación como la vía estratégica para la resolución del conflicto, en el largo plazo. El punto no es si negocia o no, sino cuándo, con qué fuerza y para obtener qué resultado.

El producto de esta situación tan asimétrica no puede ser otro que, de un lado, un Estado urgido de negociar y que para este fin hace gala de una gran generosidad y, de otro, una guerrilla renuente y esquiva para negociar, que no ofrece nada y para quien las concesiones del Gobierno son una retribución apenas obvia y natural por concederle la gracia de hablar de diálogos y por asistir a regañadientes a una negociación.

El país debe percatarse de que la nuestra es una guerra irregular y que en ella la victoria no siempre significa -por lo menos no en todos los casos- que se haya derrotado militarmente al adversario, pero siempre significa que se le ha agotado, se le ha dejado exhausto y se le ha acabado psicológicamente ${ }^{7}$. En la guerra irregular, la victoria y la derrota van llegando de manera imperceptible; por la puerta trasera, en cierto sentido. Se derrota al adversario cuando este va dejando de tener la fortaleza interior y la voluntad de defenderse. Así, el problema de dejar indefenso al adversario deviene entonces en un problema de tiempo. La guerrilla siente ahora que el tiempo la ha premiado por haber esperado y por saber esperar.

La guerrilla sólo cambiará su percepción del desarrollo de la confrontación y convendrá en negociar seriamente la paz en la medida en que disminuyan de manera sustancial sus posibilidades de expansión y de fortalecimiento. En consecuencia, el momento en que se podrá realizar un diálogo útil que conduzca a un tratado de paz estable y permanente estará más o menos cercano en función de la mayor o menor capacidad del Estado para contener a la guerrilla, y para reducir progresivamente los espacios conquistados por ella. Sólo en ese momento la guerrilla se vería obligada a negociar. Pero, por ahora, estamos en el tiempo de la guerrilla.

Es necesario revisar la evaluación que se hace del factor tiempo en el fenómeno subversivo. Es ya un lugar común entre muchos analistas plantear que a una guerrilla que lleva cuarenta años en el monte se le agotó el tiempo. Esto es cierto a nivel histórico general, pues su lucha tal vez ya no podrá cambiar radicalmente el sistema, ni realizar transformaciones revolucionarias en la sociedad: en este sentido está derrotada. Pero no es tan cierto a nivel político ni militar. En efecto, el problema no es que la guerrilla lleve cuarenta años en el monte; el problema es que en los últimos diez años ha cre- cido más que en los treinta y dos años anteriores, en términos de cobertura territorial y de hombres en armas. Las FARC, por ejemplo, pasaron de cerca de 3.600 hombres y 32 frentes en 1986, a aproximadamente 7.000 hombres y 60 frentes en 1995; el ELN, por su parte, en ese mismo período pasó de 800 hombres y 11 frentes a 3.000 hombres y 32 frentes. Y no parece que esta tendencia se haya revertido.

Lo que ha demostrado la guerrilla es que ha jugado bien a la guerra irregular, la cual es, por definición, una guerra en la que se busca desgastar al adversario y fatigarle, minarle su voluntad de defenderse, doblegarlo psicológicamente; es una guerra de gran duración y de baja intensidad militar. Al final, sobrevivirá la parte que pueda aguantar más tiempo la respiración ${ }^{8}$. El punto es que la solidez financiera que ha logrado la guerrilla la ha equipado con buenos tanques de oxígeno que le pueden estar dando el aire suficiente para obtener, con el tiempo, el mayor logro parcial posible. Mientras no se le reduzcan sustancialmente sus ingresos el tiempo corre a favor de la guerrilla.

Esta es la perspectiva del conflicto que actualmente tiene la guerrilla ante la exigua capacidad de contención militar y de control político de los municipios y de las regiones por parte del Estado. Ella sólo cambiará su percepción del desarrollo de la confrontación y de la oportunidad de la negociación en la medida en que se disminuyan de manera sustancial sus posibilidades de expansión y fortalecimiento. Insistimos: el momento en que se realizará un diálogo útil que conduzca a un tratado de paz estable y duradero estará más o menos cercano en función de la mayor o menor capacidad del Estado para contener a la guerrilla y para reducir progresivamente los espacios conquistados por ella. En la base de la infundada apelación a la buena voluntad de la guerrilla para lograr la paz podría haber una inconsciente confusión entre lo que era la guerrilla ayer -pobre, idealista y redentora-y lo que es hoy. Sólo si se le contiene y se le reduce se podrá obligar a la guerrilla de hoy -poderosa, rica y pragmática-, a comprometerse seriamente con la paz.

\section{NO HAY EMPATE MILITAR}

Bien sabemos que el problema de la guerrilla no es de carácter exclusivamente militar y que tanto en su nacimiento, en su permanencia y en su inusitado crecimiento reciente se entrecruzan factores históricos, sociales y políticos de muy complejo orden. Que en gran medida problemas como la pobreza rural, la inequidad, la crisis agraria, la corrupción administrativa, la crisis de los partidos siguen alimentando el fenómeno guerrillero y, por tanto, una estrategia estatal que busque contener, contrarrestar y solucionar el fenómeno guerrillero debe ser comprensiva y global, e involucrar y articular elementos políticos y sociales de mucha hondura. Pero es fácil constatar que el factor militar -insoslayable, tratándose de una guerra irregular- ha sido generalmente desatendido por los analistas del fenómeno guerrillero en

7. VON DER HEYDTE, Friedrich August, La guerra irregular moderna, Eir de Colombia Ltda, Bogotá, 1987, pág. 94.

8. Ibídem, pág.94. 
Colombia. El abandono de c stos temas por parte de la sociedad civil es otro síntoma de nuestro subdesarrollo político. En nuestro conflicto interno el factor militar se desestima con la apreciación equívoca de que existe un empate militar entre el Estado y la guerrilla. A nuestro modo de ver no existe ese empate militar. La guerra se puede ganar. Pero también se puede perder. Esta realidad, sin embargo, es ocultada por creencias que se han vuelto de común aceptación y tienden a permanecer inamovibles, pero que no corresponden a la dinámica de la prolongada guerra irregular que sigue desangrando al país. Esas creencias se han tomado como verdades de manera muy ligera y es preocupante verificar la forma como hasta ahora han influido en las propuestas para la solución del conflicto.

Una de estas apreciaciones erradas es precisamente la supuesta existencia de un empate militar negativo en el enfrentamiento entre el Estado y la guerrilla. En efecto, muchos analistas del conflicto interno aducen ese empate para señalar el diálogo como el instrumento único, exclusivo y excluyente, para resolver el conflicto y establecer que la política de paz del Estado debe limitarse en todo momento a buscarlo a cualquier precio sin importar, incluso, la reiterada y abierta negativa de la guerrilla a dialogar. En la base de este planteamiento está el convencimiento de que ni el Ejército puede derrotar a la guerrilla, ni la guerrilla puede derrotar al Ejército y que, además, esa situación es prácticamente inmodificable.

Para examinar este asunto la pregunta clave que debe formularse es: ¿Qué significa en una guerra irregular derrotar al enemigo? Si esto significa destruirlo y aniquilarlo por completo, sin duda que a estas alturas del enfrentamiento la solución militar no tiene ninguna viabilidad. Pero esta pretensión de aniquilamiento no corresponde plenamente a la esencia de la guerra irregular que no es solamente un enfrentamiento militar sino un combate total que involucra todos los ámbitos de la organización social, es una guerra de gran duración y de baja intensidad militar. Es fundamentalmente una guerra distinta de la.; guerras regulares que ocurren entre naciones cuyos desenlaces generalmente pasan por la destrucción o la inmovilización de la fuerza armada del adversario, casi siempre son de corta duración y de muy alta intensidad militar. Ciertamente, no es muy consistente tomar en préstamo una expresión que puede indicar un estado de cosas en la guerra regular entre naciones para tratar de explicar, de manera forzada, la situación del conflicto interno en Colombia, que corresponde plenamente a la dinámica de una guerra irregular moderna.

En una guerra irregular los criterios e indicadores victoria y derrota son obviamente distintos en cada uno de los bandos, el Estado y la guerrilla. Porque parten de situaciones distintas y tienen objetivos básicamente diferentes, tanto el establecimiento como la guerrilla deben tener distintos modos de apreciar su propia victoria y la derrota de su adversario. Creemos que la guerrilla podría tener más o menos claros estos aspectos, pero posiblemente no sea así en el lado del establecimiento.

Para el establecimiento, la derrota del adversario debería ocurrir cuando, mediante acciones contundentes enmarcadas en una estrategia general y de largo alcance, logre cam- biarle a la guerrilla la percepción que ella tiene del desarrollo estratégico del conflicto, le reduzca sus expectativas de crecimiento militar, le frene su ritmo de expansión territorial, le propine golpes de gran efecto demostrativo y le arrebate sus áreas estratégicas desde el punto de vista militar y económico. Como consecuencia de todo esto, el Estado podría someter la guerrilla a su voluntad, aún sin aniquilarla, lo que equivaldría a contenerla primero, para obligarla a negociar después. Desde esta perspectiva, debemos convenir entonces que es posible derrotar a la guerrilla incluso en el terreno militar y que no existe, en consecuencia, ese mentado empate militar negativo.

Pero, para ser rigurosamente lógicos, también debemos aceptar que contra la tesis del empate militar negativo es igualmente concebible una posibilidad hipotética de victoria de la guerrilla, en los términos limitados y relativos que hemos descrito en relación con una eventual victoria del Estado sobre los grupos guerrilleros. Antes que nada, ese triunfo hipotético y relativo de la guerrilla requiere destruir en el establecimiento su creencia en la posibilidad de victoria sobre las fuerzas irregulares. Vender la idea de que la guerrilla es invencible porque no se ha podido derrotar en cuarenta años. Pero, como una guerra irregular exitosa debe principalmente disolver el orden y la organización de los enemigos de la guerrilla, la derrota del establecimiento significa, para ella, desleír ese orden militar, civil, económico y político. Es lo que los jefes guerrilleros llaman construir factores de poder dentro del sistema, o tomarse el poder a pedacitos.

Dicha victoria hipotética se podría pensar en términos de una creciente reducción, por parte de la guerrilla, del espacio que es controlado por las fuerzas gubernamentales, una ampliación desbordada e incontrolable de su capacidad de sabotaje económico que impida de manera casi permanente el funcionamiento normal de la economía, el aislamiento de importantes núcleos de población, un serio cuestionamiento al mito de la omnipresencia y la omnipotencia del Estado, del carácter soberano, exclusivo, irresistible y sustantivo de su poder ${ }^{9}$, un agotamiento de la voluntad de triunfo por parte del establecimiento; en fin, una sensación de sin salida del conflicto como no sea el sometimiento a las condiciones que imponga la guerrilla para iniciar una negociación. En este caso, también una victoria militar y política de la guerrilla y, por consiguiente, el término de empate militar negativo tampoco tendría aplicación.

El lado problemático de aceptar el empate militar negativo para definir la actual situación del conflicto interno es que contribuye a desestimular el esfuerzo militar del Estado para obligar a la guerrilla a negociar imponiéndole las condiciones y, además, hace aparecer ese esfuerzo como poco menos que inútil e improcedente en tanto recurso de una

9. HeLlER, Herman, Teoría del Estado, Fondo de Cultura Económi ca, México, 1987,, pág.264. Para este autor, "La soberanía del Estado sig nifica, pues, la soberanía de la organización estatal como poder de ordenación territorial supremo y exclusivo. El Estado, como organización territorial soberana, es creador supremo de las normas y tiene el monopolio del poder de coacción física legítima, la última ratio de todo poder". De hecho, en Colombia la acción guerrillera sobre el territorio y sobre la población está diluyendo la soberanía del Estado. 
política de paz. Más aún: contribuye a reforzar la creencia en que cualquier acción de fuerza del Estado aleja las posibilidades de resolución política del conflicto, como si lo político y lo militar fueran excluyentes y no complementarios. Pero también -y esto nos parece más grave- ayuda a ocultar las posibilidades que, hoy por hoy, tiene la guerrilla para convertirse en un factor real de poder con capacidad para influir de manera decisoria en el curso del país en un mediano plazo. Negar de manera rotunda y emocional estas posibilidades es un peligroso menosprecio del enemigo que no le hace ningún favor al campo propio. Negarse a creer que la guerrilla le apuesta a la guerra para ganarla es, además de un irrespeto a la seriedad del adversario, una miopía muy peligrosa.

Pero, igualmente, argumentar que la guerra no se puede ganar y que la guerrilla es invencible porque no ha podido ser derrotada en cuarenta años es esencialmente un planteamiento conservador y sofístico. Conservador porque aduce que basta con que las cosas hayan sido de determinada manera en el pasado para que inevitablemente sigan siendo de esa misma forma en el futuro; también hasta el día anterior a la caída del muro de Berlín los comunistas pensaban que el comunismo era invencible porque había durado más de setenta años en Europa. Y es sofístico, porque con la misma lógica se podría decir que el establecimiento es invencible porque en los mismos cuarenta años la guerrilla no lo ha podido derrotar.

\section{OPCIONES POLÍTICAS Y MILITARES}

En definitiva, dejar hacer carrera ciertos tópicos de fácil circulación pero que no corresponden a la dinámica del conflicto no tiene otro resultado que deformar y ocultar la dirección que puede tomar la confrontación hacia desenlaces sorpresivos e indeseados, aun cuando no por eso imprevisibles.

Por tanto, en las actuales condiciones del desarrollo de la confrontación debería ser evidente que ante la renuencia de los alzados en armas a decidirse por la solución política del conflicto, al Estado no le queda otra salida que aceptar el reto de confrontación armada que le hace la guerrilla. Por parte del Estado, entonces, la guerra debería ser una continuación de su política de paz, por otros medios. Por paradójico que parezca, la política gubernamental de paz podría empezar a depender cada vez en mayor medida de lo que sea posible hacer en el terreno de la confrontación. Pero para preparar una respuesta militar adecuada al imperativo político que plantea la amenaza guerrillera, es necesaria una definición muy clara de los objetivos políticos que el Estado pretende conseguir: No hay que olvidar que la guerra y la política siempre van unidas, pero la política debe ir al comando estableciendo los objetivos para que la estrategia militar, que se ocupa por naturaleza del despliegue militar para conseguir los objetivos políticos, pueda alcanzarlos ${ }^{10}$. Aclarados los objetivos políticos se puede resolver el asunto básico de la estrategia militar, que es discernir el centro de gravedad contra el cual se debe dirigir el impulso bélico".

Frente al problema de la guerrilla podrían plantearse varias opciones políticas: a) seguir esperando de manera paciente y sin realizar ningún esfuerzo militar adicional a que la guerrilla buenamente se decida a negociar la paz, b) cancelar en definitiva la posibilidad de diálogo y decidirse a acabar militarmente con la guerrilla, y c) dejar abierta la posibilidad de una solución política, pero golpear a la guerrilla en el terreno militar para obligarla a negociar. La primera opción sería una claudicación miope y una concesión gratuita del tiempo necesario para que la guerrilla se siga fortaleciendo como hasta ahora lo ha venido haciendo. La segunda no consulta las condiciones políticas, económicas y sociales del país e ignora el tamaño del esfuerzo bélico necesario. La tercera nos parece una opción viable y, si se actúa resuelta y adecuadamente, eficaz.

Descartada de plano la primera opción, examinemos las dos últimas. Desde el punto de vista de la teoría de la estrategia militar pueden plantearse dos formas de acometer la guerra contra la guerrilla: a) como una guerra de aniquilamiento y b) como una guerra limitada. Una guerra de aniquilamiento requiere de un ejército de masa y de una muy amplia disposición de los recursos de la nación para suplir con solvencia los ingentes requerimientos del esfuerzo militar. La evaluación de los resultados se haría, principalmente, por la cantidad de fuerza armada enemiga destruida. La conquista de territorio no tendría utilidad y siempre se estaría buscando la batalla decisiva que definiera el conflicto. El aniquilamiento del enemigo se buscaría porque los propósitos políticos del adversario se considerarían radicalmente excluyentes e inaceptables, por lo que no habría lugar a ninguna transacción ${ }^{12}$.

De otro lado, una guerra limitada parte del supuesto de que el aniquilamiento del enemigo no es posible y por eso se orientaría más bien hacia su debilitamiento progresivo. Este planteamiento estratégico considera la acumulación de conquistas territoriales parciales como útil para desgastar al enemigo, para impedirle sus posibilidades de reorganizar su ejército y para minarle su voluntad de continuar el conflicto. Esta estrategia de agotamiento tiene dos polos: la batalla y la maniobra. La combinación de ambas implica, en cada momento, poder establecer cuándo se debe obedecer a la ley de la temeridad y cuándo a la ley de la economía de fuerzas. Esta guerra limitada se desarrollaría porque, de un lado, las tensiones o intereses políticos comprometidos son de tal carácter que, en todo caso, podrían ser transados mediante un proceso de negociación y, de otro lado, la disposición de los medios militares es tan restringida que la destrucción del enemigo no puede ser concebida ${ }^{13}$.

En Colombia el Ejército ha venido librando equivocadamente una lucha contra la guerrilla con características de guerra de aniquilamiento, además sin contar con los medios necesarios para aplicar cabalmente una estrategia de este tipo, o sea, sin un ejército de masa y sin una disposición sin límite de los recursos de la nación. La disposición de recursos de todo orden para realizar un esfuerzo militar orientado al aniquilamiento de la guerrilla en la actualidad no sólo

10. Von Clausewitz, Karl, De la guerra, Editorial Labor/Punto Omega, Barcelona, 1984, pág.47

11. Ibidem, pág.48.

12. Ibidem, págs.22 y ss.

13. Ibidem, págs.22 y ss. 
no es, ni mucho menos, suficiente, sino que simplemente es inconcebible, ya que de acometerse implicaría echar por la borda tanto los objetivos de modernización e internacionalización de la economía, como los programas de desarrollo social, propósitos irrenunciables en la Colombia de hoy.

Así, pues, si para lograr la reconciliación nacional la única opción viable hoy es obligar militarmente a la guerrilla a negociar la paz, la estrategia militar correspondiente sería el desarrollo decidido de una guerra limitada que busque debilitar a la guerrilla mediante la obtención de resultados parciales pero acumulativos, que incluya la batalla y la maniobra militar y política, que conceda importancia al espacio, que reconquiste territorios, que le dé importancia al tiempo como recurso limitado y escaso. Es decir, una lucha con metas concretas y plazos precisos. Es la opción que le deja al Estado una guerrilla que de manera tan reiterada ha insistido en rechazar el camino del diálogo y del entendimiento.

El principal objetivo de una estrategia de este tipo, muy aplicable a las condiciones de Colombia, que nunca ha tenido un ejército de masa, sería recuperar para el Estado el monopolio de la fuerza, de la justicia y del tributo, monopolio que ha venido siendo erosionado por la guerrilla en distintas regiones del país. Este debería ser el principal objetivo estratégico y, en consecuencia, para alcanzarlo es preciso tener muy claro el carácter territorial que adquiriría la confrontación. Este énfasis sería también una respuesta adecuada al planteamiento estratégico del adversario que ha ubicado el dominio territorial como uno de sus principales objetivos. Sin duda, en la formulación de una estrategia el Estado debe considerar tanto sus propios fines como los objetivos estratégicos de sus adversarios ${ }^{14}$.

El carácter limitado de una guerra como la que se ha planteado no excluiría sino que, por el contrario, requeriría de la más amplia movilización nacional. Puesto que en una guerra interior no existe estrategia alguna de carácter exclusivamente militar, es necesario nacionalizar, por así decirlo, el esfuerzo del Ejército, en el sentido de que su empeño sea apoyado activamente por la nación entera. Pero la primera condición para involucrar a la nación en este esfuerzo es que los asuntos militares dejen de ser de dominio exclusivo de los especialistas, y que el público en general sea instruido para poder tener un criterio y una apreciación conveniente sobre los problemas políticos y militares que condicionan la resolución del conflicto interno. La segunda condición es que el uso de la fuerza debe ser legal, ético y legítimo, dentro de los marcos legales del derecho interno y los del Derecho Internacional Humanitario.

En las guerras nacionales la opinión pública es un importante centro de gravedad: en tanto puede incidir sobre el curso político de los hechos, es un objetivo militar de vital importancia. Así debería apreciarlo el Estado.

Sin embargo, es fácil constatar que, hoy por hoy, la sociedad colombiana no parece querer comprometerse en una lucha a fondo contra las guerrillas. Se tiene la confianza en que la solución del problema es más o menos cuestión de dejar pasar el tiempo; sobre todo en los centros urbanos ha prevalecido la impresión de que, a pesar de lo preocupante de su crecimiento, la guerrilla no amenaza de manera inminente y grave la existencia del actual orden social y político.
A medida que los motivos para la acción contra la guerrilla se hacen más débiles, tanto más esas acciones se convierten en una especie de resistencia pasiva y tanto menos parece requerirse de principios orientadores. El enfrentamiento militar se ha rutinizado y está determinado, ante todo por la prudencia; el principal objetivo parecería ser prevenir que la actual correlación de fuerzas se vuelva súbitamente en contra del Estado y que esta guerra a medias se convierta en una guerra verdadera ${ }^{15}$. El método que predomina es la amenaza al enemigo, su descalificación... y la negociación sin norte ni guía.

Daría la impresión de que, frente al problema, la cuestión es que cada uno se arregle lo mejor que pueda y espere a que en el futuro se presenten acontecimientos favorables; aun cuando sea endeble la base para esa esperanza, son fuertes los deseos, y así se alivia en algo el peso de la incertidumbre. En el entretanto, el país arrastrará la guerra penosa y débilmente, al igual que un cuerpo agotado y rendido por la enfermedad. Cunde la creencia de que la llamada guerra integral del gobierno del presidente Gaviria ya significó el máximo esfuerzo realizable por parte del Estado y de la sociedad contra las guerrillas. Y, claro, si así fuera, una vez realizado ese máximo esfuerzo sin haber obtenido los resultados esperados, pues habría que concluir que la confrontación es inútil, que todo esfuerzo es vano, que la cosa está casi perdida por esa vía. Ni más ni menos que aceptar una rendición, de pronto condicional, pero rendición al fin y al cabo.

Mientras tanto el reto subversivo sigue creciendo al amparo de las crisis nacionales que no le han permitido al país ocuparse verdaderamente del problema. Primero fue el narcoterrorismo, que demandó tantas energías nacionales para superarlo, después fue el 'proceso 8.000' que mantuvo en vilo al país. Parece como si las energías del país no dieran sino para concentrarse y tratar un solo problema cada vez y nunca dos simultáneamente. La guerrilla sigue pelechando al cobijo de un país distraído en otros asuntos, sigue creciendo en una suerte de atrincheramiento expansivo que le permite, al mismo tiempo, rehuir la confrontación y ampliar su poder territorial.

Cuando se le exige al Ejército presentar resultados, ¿de qué resultados se está hablando? De hecho, hasta hace poco el Ejército no había dejado de obtener resultados tácticos favorables... que escondían resultados estratégicos muy desfavorables. No se comprendía que en una guerra irregular se pueden tener todas las victorias tácticas posibles y, simultáneamente, estar otorgando ventajas estratégicas al adversario. En breve, se estaban ganando todos los enfrentamientos con la guerrilla y se le propinaban muchas bajas, pero simultáneamente la guerrilla había continuado creciendo en forma geométrica y ampliando sin pausa su influencia en zonas cada vez más cardinales para la marcha económica y política del país.

14. T. FISHEL, John, "The Principle of Unity of Effort: A Strategy for Conflict Management", en MANWARING, Max G. y Olson, Wm. J. (eds.), Managing Contemporary Conflict, Westview Press, Colorado, USA, 1996, pág.176. Citando a Sun Tzu, el autor recuerda que "es de suprema importancia en la guerra atacar la estrategia del adversario".

15. Véase Von Clausewitz, Karl, Op.cit., pág. 320. 
¿Por qué? Porque el Estado no ha tenido un planteamiento estratégico claro, porque los objetivos políticos y militares en la lucha contra las guerrillas no son claros. $O$, poniendo las cosas en el orden debido, no hay una respuesta militar adecuada porque no hay unos objetivos políticos claros ${ }^{16}$. Ponerse de acuerdo en que tarde o temprano el conflicto se va a resolver por la vía de la negociación, como al parecer nos pusimos de acuerdo la mayoría de los colombianos hace ya más de diez años, no constituye de por sí una estrategia. Porque para llegar a esa situación no se ha señalado un camino. Para llegar a la negociación, ¿se debe vencer a la guerrilla? ¿O se debe convencer? ¿Se debe reducir? ¿Se debe aniquilar? ¿Se debe debilitar? ¿Se debe arrinconar? Definido este punto esencial se debe responder por el cómo, en cuánto tiempo y con qué recursos. Esto sería articular una política y definir una estrategia de Estado a largo plazo.

Es necesario definir en términos de objetivos políticos tanto el tipo de guerra que se decide emprender, como los objetivos militares adecuados. Nada de esto excluye, sobraría decirlo, que se mantenga la puerta abierta para solucionar el conflicto por la vía de la negociación política. Lo que no configura una política es mantener la puerta abierta y esperar a que buenamente el adversario entre a dialogar. Porque entonces se declina la iniciativa en favor del otro y se entrega la propia voluntad al albedrío del contrario. Al país le está ocurriendo con la guerrilla lo mismo que le sucedió con el narcotráfico: no quiso ver durante largo tiempo la magnitud de la amenaza hasta que el costo de la convivencia se tornó demasiado alto y el sacrificio para erradicarlo muy grande.

Así pues, la peor situación es la falta de estrategia y la persistencia en el error; si no se tiene un marco de referencia, unos principios orientadores, se pueden malinterpretar las intenciones del adversario, subestimar su capacidad, subvalorar la dimensión de la amenaza, equivocar la apreciación de la naturaleza del conflicto. A partir de ahí se pueden imponer límites inconvenientes al esfuerzo, creer que mantener una guerra de baja dimensión lleva a ganarla, exigir a los militares más de lo que pueden dar las solas armas, equivocar la apreciación de los resultados, confundir la valoración de los aliados y de los adversarios, percibir tardíamente el cambio en el curso de la confrontación, ir perdiendo la guerra sin darse cuenta y no reaccionar oportunamente para corregir el rumbo.

Aun cuando no debiera servirnos de consuelo, es bueno señalar que lo que nos está sucediendo en Colombia no es ni mucho menos excepcional. Ocurre hasta en las mejores familias. Aunque por su naturaleza y sus connotaciones geopolíticas no sea comparable con el conflicto interno colombiano, la participación norteamericana en la guerra del Vietnam ya es un ejemplo arquetípico de cuan complicado puede ser el cambio de los rígidos esquemas mentales y de su desastrosa influencia en la definición de las políticas. Después de más de veinte años de terminada la guerra del Vietnam, la sociedad norteamericana todavía no ha podido ponerse de acuerdo sobre cuáles fueron las lecciones de esa guerra, ni sobre cuáles fueron las razones para perderla ${ }^{17}$. La diferencia es que, en Vietnam, los Estados Unidos se jugaban su orgullo, en cambio en Colombia nos podemos estar jugando nuestro futuro como nación, porque la prolongación de la guerra nos está haciendo perder tiempo precioso para el desarrollo y el progreso. De ahí la necesidad de aprender más rápido.

16. General BEAUfRE, La estrategia de la acción, Editorial Pleamar, Buenos Aires, 1973 , págs. 32 y ss.

17. Sobre este punto véase, por ejemplo, a NIXON, Richard, No más Vietnams, Editorial Planeta, Bogotá, 1986 y también a MCNAMARA, Robert S., In Retrospect, Times Books, Random House, New York, 1995. Mientras, según Nixon, Estados Unidos ganó la guerra y perdió la paz, para MacNamara fueron los errores de apreciación y de juicio de sus líderes los que llevaron a Estados Unidos a perder la guerra.

\section{RESUMEN}

El artículo analiza las transformaciones de la guerra irregular de las guerrillas colombianas en las últimas décadas. Para ello, se estudian los cambios que han afectado a distintos factores, como los objetivos estratégicos, los medios financieros, militares, las relaciones que mantienen con los partidos políticos tradicionales en el nivel local, sus parámetros ideológicos, el origen social de sus miembros. Con esta perspectiva, se analiza el cálculo político/temporal que la guerrilla hace en la actual coyuntura y sus consecuencias para el proceso de paz.

Palabras clave: guerra irregular, guerrillas, Estado colombiano, paramilitarismo, proceso de paz

\section{ABSTRACT}

This article examines the transformations of the irregular war of the colombian guerrillas, studying the changes of several factors such as the strategic goals, the financial and army resources, the relationship among the political parties in the local level, the evolution of their ideological parameters and of the social origin of their members. With this perspective, the author analyses temporal and political calculation that the guerrilla makes at this point, and its consequences for the peace process.

Key words: irregular war, guerrilla, Colombian State, paramilitarism, peace process. 